Portland State University

PDXScholar

Spring 7-20-2017

\title{
Policing in an Era of Sousveillance: the Influence of Video Footage on Perceptions of Legitimacy
}

Megan Elizabeth Mohler

Portland State University

Follow this and additional works at: https://pdxscholar.library.pdx.edu/open_access_etds

Part of the Criminology and Criminal Justice Commons

Let us know how access to this document benefits you.

\section{Recommended Citation}

Mohler, Megan Elizabeth, "Policing in an Era of Sousveillance: the Influence of Video Footage on Perceptions of Legitimacy" (2017). Dissertations and Theses. Paper 3678.

https://doi.org/10.15760/etd.5562

This Thesis is brought to you for free and open access. It has been accepted for inclusion in Dissertations and Theses by an authorized administrator of PDXScholar. Please contact us if we can make this document more accessible: pdxscholar@pdx.edu. 
Policing in an Era of Sousveillance: The Influence of Video Footage on Perceptions of Legitimacy

by

Megan Elizabeth Mohler

A thesis submitted in partial fulfillment of the requirements for the degree of

\author{
Master of Science \\ in \\ Criminology and Criminal Justice
}

Thesis Committee:

Christopher Campbell, Chair

Brian Renauer

Kelsey Henderson

Portland State University

2017 


\begin{abstract}
The current climate surrounding the police in the United States could be described as strenuous. This is large in part due to certain shifts in technology and news disbursement; citizens now have the ability to record and share police-citizen encounters. Certain controversial events have been captured and undoubtedly have contributed to a growing mistrust towards the police, evident by the development of movements for police reform. Within the field of criminology, perception of police legitimacy has been a long studied concept. Research has shown that when the police are viewed as legitimate, the public is more likely to cooperate and comply. Thus, the possible decrease in the public's legitimacy perceptions of the police is deeply concerning.

In this study, a randomized experiment was employed to measure the influence of video footage of police-citizen interactions on individual's legitimacy perceptions. Participants were randomly selected to watch videos that showed the police acting in ways that were either positive, negative, or neutral. Legitimacy perceptions were measured before and after exposure to the videos. Analysis of the pre-test and post-test scores showed the videos did influence perceptions: negative videos had the largest influence and significantly decreased perceptions, whereas, positive and neutral videos both significantly increased legitimacy perceptions. The results of this study holds implications for both the police and the public.
\end{abstract}




\section{Acknowledgments}

I would like to acknowledge the help and guidance I received from all faculty in the Criminology and Criminal Justice Department at Portland State University. Thank you for igniting my interest in research and providing me with a solid foundation to continue my academic career. This program has provided me with great direction and has been incredibly motivating.

I would like to especially thank my thesis committee: Dr. Henderson, Dr. Renauer, and Dr. Campbell.

Dr. Henderson, thank you for your excellent guidance in experimental research and quantitative methods. Your contributions to my thesis have been invaluable.

Dr. Reanuer, thank you for introducing me to the world of policing studies, especially to the theories of procedural justice and legitimacy perceptions. Without this knowledge, this thesis would not be possible.

A special thank you is extended to my committee chairperson and advisor, Christopher Campbell. Thank you for motivating me throughout the entire program. Thank you for your guidance and dedication. Your help has been immeasurable. 


\section{Table of Contents}

Abstract.......................................................................

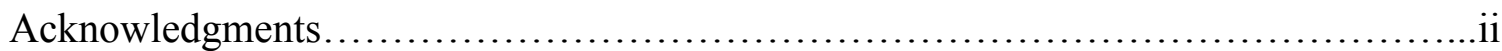

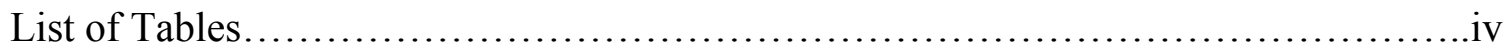

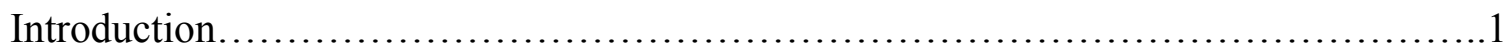

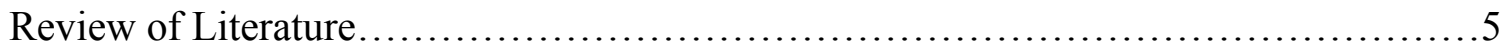

Methods...................................................................... 17

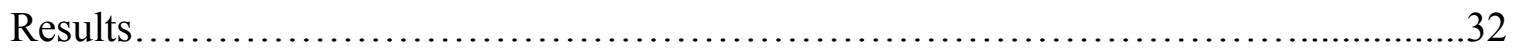

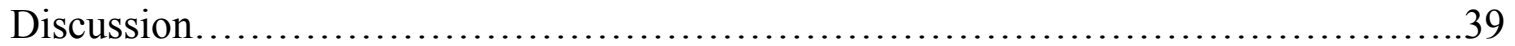

References.............................................................46 


\section{List of Tables}

Table 1: Demographic Differences Between the Groups....................................33

Table 2: Zero Order Correlations for Pre-test Variables...................................34

Table 3: Changes in Measures After Video Exposure......................................38 


\section{Introduction}

Police have long struggled to maintain public perceptions of legitimacy, but in recent years it has become a more pressing issue. The rise of digital media technology and internet usage has contributed to an abundance of raw video footage documenting police-citizen interactions. Certain high profile events chronicled through citizen's cell phones, police body worn cameras, or other forms of video recording have been shared with the public, often through social media. A concept that relates to this phenomenon has been dubbed "sousveillance" (Mann et al. 2002)—a form of watching from below, or the inverse of surveillance. Traditionally, the public was considered "the watched" and the police "the watchers", but these roles are becoming inverted. The culmination of these events have resulted in a social context that is hyper-aware of police misconduct, spurring social movements for police accountability and transparency. This presumably has implications for perceptions of police legitimacy, which this study will seek to address.

For more than thirty years the public perception of police legitimacy has been an important topic of study in the field of criminology and criminal justice. In a democratic society it is important that the police are viewed as a legitimate entity by the public; when viewed as legitimate, citizens are more likely to corporate and comply with law enforcement, thus maintaining social order (Murphy, Hinds, \& Fleming, 2008; Reisig, Bratton, \& Gertz, 2007; Tyler 1990; Tyler \& Fagan, 2008; Tyler \& Huo, 2002). This cooperation from the public could lead to police performing in a more effective way to 
reduce and prevent crime, because citizens will be more likely to report crime and to assist in criminal investigations (Tyler \& Fagan, 2008). Furthermore, this falls inline with community policing models, which propose that it is necessaryto develop good relationships with local residents in order to more efficiently deal with the issues facing the community (Lersch \& Hart, 2011). Law enforcement agencies across the U.S. have been adopting this practice, at least in part, since it was first developed in the 1970's. If these agencies truly wish to shift towards community policing practices, it is imperative that the police focus on improving and maintaining favorable attitudes from the public in order to support a strong relationship and communication. Public perception of police legitimacy has become an even more critical topic in recent years. This is evident by the creation of the President's Task Force on $21^{\text {st }}$ Century Policing which created a Report in 2015 to address the issues surrounding policing. Among other recommendations, the report strongly suggests that policing agencies adopt a community policing model and focus on acting and proceeding in a way that would be perceived as legitimate. This report was created, at least partially, in response to public pressure.

The current societal context could be described as hyper-aware of problematic police conduct. Several controversial incidents, in a short period of time, have brought forth unprecedented attention surrounding police misconduct and debates on reform (Weitzer, 2015). Public attention towards high-profile incidents of police-citizen interaction is not a new phenomenon. Research on many past incidents shows that these highly publicized, controversial interactions typically erode public confidence for a short period of time following the occurrence but public opinion usually rebounds back to 
previous levels (Weitzer 2002; Graziano, Schuck, \& Martin, 2010). While this might be true of past decades, the current climate might hold different implications.

When consecutive events occur in a condensed time period and receive massive attention in the media, it can damage attitudes towards the police where the incident took place but can also impair the reputation of police nationwide (Weitzer, 2002). This cumulative effect incurrently taking place in the United States, with the catalyst being the events that took place in Ferguson, Missouri during August of 2014. After the shooting and death of an unarmed Black teenager by a White police officer who a grand jury declined to indict, there was an outbreak of protests against the police. This unrest in Ferguson caught national attention and led to individuals joining together in a movement across the country to address what they consider injustice at the hands of the police (e.g., the Black Lives Matter organization). Many of the groups fueling the movement have called for greater transparency and to hold police accountable for their actions (Derickson, 2016). One popular method to achieve this is the use of smart phones and other recording devices to document police-citizen encounters. In the two years following the Ferguson events, more controversial police encounters have occurred, further straining the relationships between citizens and police.

The current social environment, riddled with concerns regarding police legitimacy, has been dubbed the 'post-Ferguson era' or 'The Age of Ferguson' (Bernard, 2015). In this post-Ferguson era, the country has experienced a shift in the social and technological landscape, which is changing the way citizens are informed about news. This shift, which is characterized by pervasive tools of surveillance (i.e., cell phones, 
security and police body cameras) and the ability to share video recordings through social media, offers a new window on encounters between police and citizens (Derickson, 2016). Previously, the public learned about questionable police encounters through mainstream media outlets, which have the ability to frame and control the story. This is rapidly changing due to "citizen journalism", a form of journalism in which an ordinary citizen can participate by recording, generating, and sharing news worthy events. This ability allows citizens to confront issues of police transparency and accountability (Farmer \& Sun, 2016; Antony \& Thomas, 2010; Greer \& McLaughlin, 2010). This shared content is available for the public to see and consequently form opinions. While previous studies have been conducted on traditional crime media, such as television news and newspapers, implications of this new technological trend on public perceptions of police legitimacy are currently unknown.

The current study will examine the effect of "viral" police-citizen videos on perceptions of police legitimacy. The videos will be classified into three categories; videos that show the police acting in a positive, neutral, or negative manner. Before exposure to the videos, a measure of police legitimacy will be collected using a questionnaire. Participants will be asked about their views towards the police as well as relevant personal information. Following this, the participants will be placed in to one of three groups and watch the corresponding videos. After exposure to the video clips, a measure of police legitimacy will be collected to examine the influence the videos had on possibly changing their perceptions of legitimacy via judgments of procedural justice. 


\section{Police Legitimacy}

Perceptions of police legitimacy refers to how the public views the police and their willingness to recognize police authority. It is more than just general public support, rather it is the public's inclination to obey the police and the law (Braga, Winship, Tyler, Fagan, \& Meares, 2014). Tyler (2004) explains police legitimacy as "the belief that the police are entitled to call upon the public to follow the law and help combat crime and that members of the public have an obligation to engage in cooperative behaviors" (p. 8687). Thus, increased perception of police legitimacy is associated with an increased obligation to obey police orders and the law. Another component of police legitimacy, is trust in the character and motivations of the police authority (Tyler \& Huo, 2002). When evaluating police, citizens are concerned with why the police are taking certain actions. When viewed legitimately, people will trust that the police are acting in a way to protect and help the public, and are not motivated by other types of selfish desires. Police legitimacy can therefore be understood as a two-part conceptualization: the perceived obligation to obey and trust in police authority.

Given this definition of police legitimacy, it is clear that such a construct has important implications in a democratic society and for police effectiveness. For a society to function it is necessary that police are looked at as authority figures who have the right and duty to maintain social order. Such power in legitimacy has been demonstrated in recent research, which has shown that when police are perceived as legitimate, the public is more likely to cooperate and comply with police orders (Murphy, Hinds, \& Fleming, 2008; Reisig, Bratton, \& Gertz, 2007; Tyler 1990; Tyler \& Fagan, 2008; Tyler \& Huo, 
2002). This link between legitimacy and compliance shows how important it is for the police to influence perceptions of the public to be more favorable, or increase legitimacy. Tactics aimed at increasing perceptions of legitimacy allows the police to avoid relying so heavily on traditional, aggressive deterrence strategies to demand compliance. Public cooperation is also important as the police often rely on the public's assistance to do their job. For example, increased cooperation can result in an increase in crimes being reported and an increase willingness to assist the police by providing information relevant to a case. Voluntary compliance, which is a byproduct of legitimacy, is also beneficial in police interactions for the safety of the officers and the citizen (Tyler \& Huo, 2002). When forced compliance is elicited by the police due to a proclamation of power, it can result in anger and resentment from the less powerful subject as a means to resist and harm the aggressor (Lawler, Ford, and Blegen, 1988). This resistance can put both the citizen's and the officer's life in danger, as the officer makes attempts to maintain power and control of the situation. In comparison, when the interaction is centered around fairness and mutual cooperation, tension resulting from dominance can be alleviated (Sunshine \& Tyler, 2003

Considering the importance of police legitimacy, much research has been conducted on the antecedents of legitimacy. There are competing theories as to how people form perceptions of legitimacy (e.g., instrumental model, distributive justice model, police performance model), but research has found the most support for Tyler's (1990) procedural justice model (Jackson et al., 2012; Sargeant, Murphy, \& Cherney, 2014; Sunshine \& Tyler, 2003; Tyler, 2005; Tyler \& Huo, 2002). This perspective argues 
that people form their perceptions regarding police legitimacy based on judgments of procedural justice, or the fairness of police procedures. In this approach, police legitimacy is connected to public assessments about the fairness of police decision making and the quality of treatment (Jonathan-Zamir and Weisburd, 2013; Sunshine \& Tyler, 2003; Tyler 1990, 2003; Tyler \& Huo, 2002). Tyler (2004) suggests that there are four key elements to procedural justice judgments: (1) participation—allowing citizens a chance to explain and communicate their view; (2) neutrality—making decisions unbiasedly and based off of objective information; (3) respectful treatment—-being polite and treating people with dignity; and (4) trustful motives - genuine intentions that show care for the well being of citizens.

Previous research demonstrates that when citizens evaluate the police they focus more on how they treat people than how well they perform their job (Tyler 1990; Tyler \& Huo 2002; Tyler 2001). Respectful or fair treatment by the police means that they treat the citizen with courtesy and dignity, allow the person a chance to express their views before decision making, try to help the citizen when possible, and clearly explain the reasons for their decisions (Sunshine \& Tyler, 2003). It is important to note that this model has found support across all people and suggests that these judgments are more important than individual differences when it comes to predicting legitimacy perceptions. Historically, there has been noted ethnic group difference in and confidence towards the police. Tyler and Huo (2002) examined this issue and found that procedural justice is equally important to whites, African Americans, and Hispanics. Not only is this phenomenon found across ethnicities, research suggests that the importance of procedural 
justice is also upheld across gender, income, education, age, ideology and political party (Tyler 1994, 2000).

Prior research that has looked at relationship between procedural justice and legitimacy primarily uses survey data (Sunshine and Tyler 2003; Tyler and Fagan 2008). Sunshine and Tyler (2003) conducted a mail survey with 586 New York City residents. With that data they conducted a regression analysis with a model accounting for $73 \%$ of the variance in perceptions of legitimacy. The model indicated that legitimacy was based predominantly on procedural justice. To follow up on these results, 1,653 telephone interviews were conducted with New York City residents. The researchers again found the primary antecedent of legitimacy to be procedural justice.

Tyler and Fagan (2008) compared a performance based model to a procedural justice model to determine which had a stronger link to legitimacy perceptions. To do so, they utilized a longitudinal design by administering two surveys to 830 participants a year apart from one another to measure opinions towards the police. They were further interested in analyzing how these opinions changed for those who had a personal encounter with the police during the year in between the two surveys. The results of this study found that legitimacy was primarily linked to judgments of procedural justice over performance based model. Furthermore, people who had an experience with police and received a negative outcome, still reported an increase in legitimacy if they perceived the experience to be procedurally just. This suggest that judgments of procedural justice are more important than outcome evaluations when it comes to forming perceptions of legitimacy. 
In these studies, and much of the other research examining procedural justice and legitimacy, respondents had been asked to recall and judge past encounters with the police. This is problematic in that not all citizens have had experiences with the police and there is often issues with memory recall. Thus, to build upon this work it is vital to conduct experiments in which researchers could gather information on specific encounters as they occur or right after they occur.

Another study aimed to examine the influence of procedural justice versus police performance evaluations in relation to legitimacy perceptions under a unique circumstance. Jonathan-Zamir and Weisburd (2013) used survey data and a natural experiment design to understand how security threats might alter antecedents of police legitimacy. The researchers thought it might be possible that under a security threat, citizens might place more value on police performance than procedural justice. Two sample communities in Israel were compared —one with no active security threat and one community that was facing a threat to security. Surveys measuring procedural justice, police performance, and legitimacy perceptions were administered to both communities. While the researchers did find that performance evaluations played a more significant role in predicting police legitimacy in the community under a security threat, procedural justice remained the strongest antecedent of legitimacy in both communities, further showing just how strong the link is between procedural justice and legitimacy perceptions.

To address the problem of recalling on past experiences, one experiment was designed so that participants could evaluate the police through a vicarious experience. 
Braga and associates (2014) conducted a randomized factorial experiment in which they first gave participants a vignette describing the context in which an arrest took place, followed by exposure to a video of an actual police-citizen encounter. They found that the perspective a person has prior to evaluating the situation can have a considerable influence regardless of what actually occurred in that situation. The procedural justice (or injustice) experienced by respondents in their most recent encounter with the police impacted their assessments of the police in all videos. If the participant had a prior interaction where they believe the police treated them disrespectfully and unfairly, they negatively evaluated the police in the video. Thus, this implies that personal experience can be more influential than a vicarious experience via video exposure. As this study was conducted a few years ago, it is possible that over time, with the abundance of policecitizen videos shared via social media, that there might be a more substantial impact of video exposure. To date there has been no formal study on the effect of citizen recorded and shared policing encounter videos on the effects of police legitimacy. It is important to understand how judgments of procedural justice concerning these policing videos influence perceptions of legitimacy.

\section{Police and Media Relationship}

A key component for policing organizations in establishing and maintaining legitimacy is the ability to manipulate and control their external environment. The $21^{\text {st }}$ Century Policing Task Force Report (2015) suggested that it can be advantageous to develop a working relationship with the media, specifically, news outlets. By doing so 
they can communicate correct information on a case, increase transparency, call upon the public for help, and frame stories in a way that is positive towards the police. Police departments have gone so far as to appoint public information officers, to manage their relationship with the media. This allows the department to strategically manage their public image by responding proactively to scandals, manufacturing support for activities, and providing information and data to satisfy media inquiries (Chermak \& Weiss, 2005).

Previously, people often learned about news regarding the police through the television and the newspaper, but research is suggesting that the internet is moving into the role as the primary news source. Pew Research Center (2016) found that 50\% of 18 29 year olds and $49 \%$ of $30-49$ year olds reported that they primarily got their news via online sources. In comparison, television was the primary news source for the majority of $50+$ year old respondents. As society transitions towards using the internet as a primary source for learning about news, police organizations must acknowledge this in their relationship with the media.

Social media is a new element to consider in the relationship between the internet and police, and it has been understudied to this point. Social media is a group of new internet technologies that are designed for social interaction, such as Twitter, YouTube, and Facebook. Differing from previous websites, they provide a platform for interactions between users and allows for engagement by users to obtain information they are specifically interested in (Meijer \& Thaens, 2013). This means that police and citizens now have a new platform in which interaction can take place. Evolving with the technological trends, police now have another way of controlling their image through 
social media, which is a quicker and more direct route compared to working with news agencies. Public information officers now have an immediate way of controlling media presence. Police agencies can use their own personal social media pages to share information with the public as an attempt to increase perceptions of legitimacy. This type of media outreach increases legitimacy by increasing transparency, allowing the community to assist in decision making, establishing new intelligence and partnerships, and appearing more accountable to the public (Rosenbaum, Graziano, Stephens, \& Schuck, 2011).

One study looked at how certain police departments used social media accounts as a community policing tool to enhance collaboration with the community residents (Brainard \& Edlins, 2015). This descriptive study examined how the police forces in the top 10 most populous U.S. cities used social media. Findings indicated that citizens are responsive to police social media but there is limited interaction due to nonresponsiveness of the police departments, thus very little of the dialogue was collaborative. This study did not look at how video content shared by police departments could influence perceptions of police legitimacy.

The function and influence of police social media pages are further complicated in the current era of sousveillance. Just like citizens, police also have the ability to share videos to increase transparency and shape attitudes of the public. Policing organizations can use their social media to share department videos taken from body worn cameras, dashboard cameras, or helicopters, among other sources. In some ways this can be seen as a way to counteract the role inverse experience at the hands of sousveillance; the 
police can release these videos in an attempt to affirm their position as 'the watcher' and increase positive perceptions of officers. On the other hand, these videos might be released due to intense public demand after controversial events. In this way, the videos are acting as a way of sousveillance since the public gets the experience as 'the watcher' with the police serving as 'the watched'. Regardless, policing organization would be well advised to use social media and the internet as a method to increase legitimacy which in turn could increase cooperation and compliance from the public.

\section{Crime Media Effects Research}

With the rise of the internet and advances in technology, media consumption is at an all time high. It is becoming increasingly more important to understand how media influences beliefs, expectations, and attitudes. Prior media research on television viewing has shown support for the resonance hypothesis, that the influence of the content was elevated when the viewer could relate the information to their own experience (Gerbner et al., 1980). This represents the concept of audience agency, which is the active engagement by the viewer in processing the information and constructing meaning.

Given the similarity of experiences that individuals in the same socio-demographic strata share, they may interpret media messages similarly but differently from those in other socio-demographic spaces (Livingstone et al., 2001). This is especially relevant to how policing media is viewed and interpreted, given the extreme difference in experiences people with lower socio-demographic standing tend to have with police. Prior research on interpretation of crime-related media has shown the variables of gender, age, class, 
race/ethnicity, area of residence, and prior experience with criminal victimization to be the most influential factors (Chiricos, Eschholz, \& Gertz, 1997; Eschholz et al., 2002). Furthermore, research has shown that media consumption tends to have less influence on attitudes and beliefs than prior experience with the criminal justice system or individual differences (Callanan \& Rosenberger, 2011; Braga et al., 2014). Nonetheless, people are now being exposed to different types of crime/policing media, in the form of raw video footage. This footage shows how actual police-citizen interactions play out, thus a viewer has the opportunity to make judgments of procedural justice. As previous research has noted, the importance of procedural justice and its link to legitimacy has been found across many individual and group differences. Therefore, it is possible that these individual differences might play less of a role when people are viewing actual interactions in which they can make judgments of procedural justice.

Beyond individual differences, type of media consumption might have an influence of attitude formation as well. Newspapers that report on crime or policing stories will typically provide context and detailed information, which could lead the reader to making more informed opinions. In comparison, television news reporting provides much less detail and are framed in way to elicit emotional responses. Due to these differences, research suggests that television viewers are more likely to assume individual-level causes of crime compared to newspaper readers. Furthermore, consumption of television news, which often lacks context and can be sensationalized, produces more fear than reading about crime in the newspaper (Chiricos et al. 1997, Romer et al. 2003). It is possible that this relationship is also true of news stories that 
cover controversial police-citizen encounters. As the platform for news information expands into the world of the internet and social media, it is possible that people are seeing even shorter video clips with less context, which could exacerbate the negative effects found with television viewing. On the other hand, in depth news stories posted through online news outlets are more readily available and abundant than when they were previously only available through physical newspapers.

An experiment by Graziano et al. (2010) showed how media manipulation by the police can influence public opinions. In this study, video clips from a television news media outlet of a specific highly publicized police misconduct case were played to participants to determine the effect that media constructions have on influencing public attitudes. The case was an incident of possible racial profiling by Chicago police, but the news clip shown to participants was a follow up to the incident that showed a representative from the police department explaining the danger that traffic stops pose to officers. Results of their study showed that media can influence public attitudes towards the police: all participants were less likely to believe that Chicago police officers engaged in profiling and had an increased perception of the dangerousness of traffic stops after exposure to the video. These findings suggest that police can utilize media connections to frame incidents in their favor. The implications of these results are complicated by sousveillance and citizen journalism.

Another area of research that is pertinent to understanding the effects of criminal justice related media, is the research done on pre-trial publicity (PTP). Generally, studies on PTP have shown it to have a negative influence on both pre-trial and post-trial 
judgments of defendant guilt (Studebaker \& Penrod, 1997). The level of influence has also been shown to vary by type of PTP. Results from a meta-analytic review showed that those who were exposed to negative PTP were significantly more likely to evaluate a defendant as guilty those those exposed to less negative or no negative PTP (Steblay et al., 1999). The findings from this research might be transferable to the effects of viewing police-citizen media, in that exposure to negative video clips might have a more significant impact on changing perceptions.

The rise of the internet as the primary medium for news, as opposed to television, could have implications for the power of media to influence attitudes and perceptions (Pew Research, 2016). Media studies have suggested that whatever new medium is being consumed may not matter, if the messages do not change (Callanan \& Rosenberger, 2011). But, one could argue that the message is now changing. Citizen journalism has allowed the citizens the power to frame media messages. Prior, the police have had much more control framing the message by developing relationships with news outlets. As this changes, and more graphic and disturbing videos are released by concerned citizens, it is possible that media will start to have more of an influence. With the proliferation of police-citizen encounter videos available at an unprecedented rate in a new medium, it is possible that this media content will start to have a greater influence on perceptions.

Both the police and the public have the ability to use social media to help foster certain attitudes towards the police. What is unknown is how much these efforts actually do change the public's perceptions. Prior research has shown the most important influencer of an individual's perception is personal interaction with the police (Sunshine 
\& Tyler, 2003). It stands to reason that people who engage in watching police encounter videos could be influenced by these vicarious interactions. It is important to know to what extent people are affected by these videos and whether or not positive or negative videos have more of an effect. Police can use this information to their advantage to increase their perceptions of legitimacy. Furthermore, it can hold police more accountable if they are aware that recorded and shared citizen interactions can influence legitimacy perceptions.

\section{Methods and Data}

The present study seeks to primarily answer if exposure to videos of police-citizen interactions influence perceptions of police legitimacy and if the level of influence depends on the content of the video. Answering this questions will advance the literature in important ways. To date most support has been found in favor of procedural justice as the primary antecedent of legitimacy, yet there is uncertainty around the link between video clips showcasing varying degrees of procedural justice and influencing perceptions of legitimacy.

Based off of the previous literature, I hypothesized that exposure to videos that show the police acting in a procedurally just manner will increase an individual's perception of police legitimacy. While exposure to negative videos that show the police acting rude, disrespectful, using excessive force, or otherwise acting in a way deemed as procedurally unjust will decrease legitimacy perceptions. This falls in line with the prediction that procedural justice judgments will be the primary antecedent to legitimacy 
perceptions. I was further interested in comparing the influence of videos that showed the police engaging in extra community building activities and the police engaging in typically duties in a way that is deemed as fair or procedural just. Both types of videos could be perceived as "positive" but in this study they were separated into two categories, positive and neutral, respectfully. Thus a second aim of this study was to explore what type of content might be most beneficial in increasing legitimacy perceptions. In comparing the content of videos, it is also hypothesized that videos with negative content will have the largest influence. This is predicted due to prior media effects research on pretrial publicity, which has shown negative PTP to have the greatest effect on verdicts.

To answer these questions, this study used data obtained from questionnaires administered to online survey takers. This data was analyzed to address the causal link between exposure to police-citizen interaction videos and perceptions of police legitimacy.

\section{Sample}

The sample for this study was obtained through Amazon's Mechanical Turk (MTurk) population. The total sample size was 173 participants, randomly split into three groups, with 56 individuals in the neutral condition, 62 in the positive, and 55 in the negative. MTurk has been used as a survey outreach tool in thousands of previous academic social science research studies (Stewart et al, 2015). For this study, only people that reside in the United States were eligble to participate. On average, MTurk workers tend to be younger (about 30 years old), have a higher education level, underemployed, 
less religious, and more liberal than the general U.S. population (Berinsky et al. 2012;

Paolacci et al., 2010; Shapiro, Chandler, \& Mueller, 2013).

As a whole, MTurk workers differ slightly from the general population, but are very similar when compared to demographics from a certain high-quality internet survey, the American National Election 2008-09 Panel Study (ANESP). Due to the extensive and randomized nature of this survey, the ANESP is considered a high-quality internet sample (Berinsky, Huber, \& Lenz, 2012). Within the United States, Blacks and Hispanics are underrepresented in MTurk, when compared to the ANESP internet sample and highquality, face-to-face samples (Berinsky et al., 2012). While there are some concerns over external validity when using an internet sample, this is less of a concern for this study since I was interested in the perceptions of internet social media users. That being said, there are further benefits of using MTurk workers for social experiments as they tend to be closer to the U.S. Population as a whole than traditional university subject pools (Paolacci et al., 2010). The subject anonymity is also an advantage in that the Institutional Review Boards (IRBs) are more likely to view studies in MTurk as exempt from reviews (Paolacci et al., 2010).

Videos

A search for police-citizen interaction videos was conducted through various social media outlets. The search was based on the following keywords used individually or in various combinations with each other: police video, police and citizen, police encounter, police interaction, good police, honest police, police misconduct, police 
brutality, police and community. All of theses phrases were also searched by substituting "cop" for "police". On Facebook, videos were searched for by going to News organizations web pages, such as The New York Times, CNN, BBC, and the Washington Post. A search function was available on each of the pages and a search was conducted for the phrase "Police Video". Individual police department's Facebook pages were also analyzed for the video content. YouTube was also searched using the aforementioned list. A search (using the key words) was also conducted on the social media website Reddit.

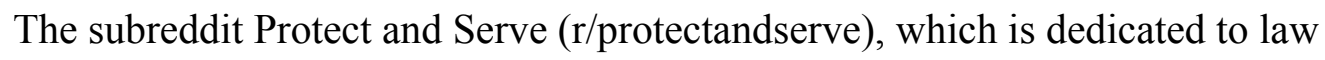
enforcement professionals, also served as a platform to search for videos. This was done by manually looking over the top posts in the past three years. The majority of the videos were found from Facebook.

The videos were all collected with tenets of procedural justice in mind. That is, the content of the video needed to show the police engaging with the community in some way, whether that was through a routine traffic stop or a community outing, all videos showed police-citizen interaction. These interactions were intended to serve as vicarious experiences in which people could make judgments of procedural justice about the police. These video are intended to serve as proxies for procedural justice judgments, but considering the lack of context, one would be less able to make judgment of distributive justice or police performance.

After the videos were collected, a Qualitrics survey was created in order to rate the content of the video into one of the three categories. This pilot survey included 18 videos in total and six individuals rated the videos. The raters were selectively chosen 
and included: (1) a policing scholar, (2) a police officer and criminal justice instructor, (3) a police officer, (4) a lawyer and professor, (5) \& (6) graduate students in criminology.

This rating survey served the purpose of increasing reliability of the study by narrowing down the selected videos that had high rater agreement in regards to the appropriate category. Participants were asked to rate the videos solely on the information presented in the clip and pick one of the three categories that best describes the content. Negative videos could include anything from unnecessary force to disrespectful treatment. The difference between positive and neutral videos was harder to define and this was apparent in the results of the rating. The instructions told the participants that a video should be categorized as positive if it depicted the police interacting with a citizen(s) in a way that goes above and beyond their typical job duties or depicted the officers in a favorable light (e.g., seems more approachable or socially warm). For instance, they might be engaging with community members by being unnecessarily helpful. Whereas a "neutral/fair" video would show the police performing a typical duty and engaging with a citizen/citizens in a way that is respectful/fair/procedural just (i.e., gives citizen voice, provides explanations). The difficulty making a distinction between these two categories is that often when a police officer acts in a way that is procedural just, it is perceived as positive. Nonetheless, the distinction of positive being more community or extra curricular related as opposed to neutral being more concerned with typical duties was emphasized to try to prevent this. 
After the videos were rated, they were categorized into the specific categories. If at least 5 out of the 6 participants agreed on the category, then the video was put into that category. If the results were more down the middle between two categories, they were put into a hybrid category. Thus, four categories were created: Negative with six videos, Positive with seven videos, Neutral with three videos, and a hybrid Positive/Neutral category with two videos. The two videos that were rated equally as both positive and neutral were reviewed again by myself. After review, I determined that these two videos could be appropriately categorized as neutral videos given that in both videos it was a police officer dealing with a traffic stop in a polite manner. This would fall in line with the idea of an officer acting in a procedural just manner during a typical duty and is not necessarily a display of positive community bonding. It seemed appropriate to have an equal number of videos for each category to try to control for the amount of exposure, thus five videos were chosen for each. This step of video rating led to a total of 15 videos being selected for the final study analysis, with five videos in each category (positive, negative, neutral).

\section{Procedure}

This study employed a pretest-posttest, experimental design using surveys and videos. The survey was designed using Qualtrics and shared via Amazon's Mechanical Turk. The videos were found through using social media and websites dedicated to recording police. These videos were classified by external raters into three categories positive, neutral, and negative. The positive videos show police engaging in a favorable 
manner to build community relations. The neutral videos show police behaving in a procedural just way during an interaction. The negative videos show police either using extraneous force, being unnecessarily aggressive, or being disrespectful. Subjects will be randomly assigned into one of the three groups to determine what videos they will be exposed to. Before the study, the participants were asked to sign a consent form which explained that they might be exposed to graphic or disturbing videos. Participants were asked to fill out a survey to measure baseline perceptions of legitimacy, procedural justice judgments and other demographic measures. The questions were adopted from existing literature on procedural justice (Sunshine \& Tyler, 2003; Wolfe, 2011). An attention check was employed during the pre-test survey portion. Participants were warned beforehand of the attention check and those who did not pass were not compensated. Using attention checks helps to ensure valid responses. In this study eight participants were excluded for failing the attention check.

After the baseline survey, participants were then exposed to five videos clips according to their assignment of either positive, neutral, or negative. A timer was placed on each video page and it would not let the participants move forward until the timer was up. This was done to make sure the video was played in it entirety. To further validate the video content coding and to make sure the participants were paying attention, a manipulation check was employed after each video. Participants were asked how they would rate the content of the video and were asked if they had seen the video before. At the end of the survey, the participants were also given a chance to write in what video left the greatest impact on them and why. After exposure to the videos, the subjects were 
asked to fill out another questionnaire, which covered many of same questions as the initial survey. This post-test was primarily concerned with measuring legitimacy perceptions after exposure to the videos. After successful completion of the survey, the participants were compensated $\$ 0.50$.

\section{Measures}

\section{Dependent variable}

The concept of police legitimacy is broken down into two elements—obligation to obey and trust (Tyler 2004; Wolfe et al., 2016). Participants were presented with six statements that capture these two elements and were asked to rate on a six point Likert scale how much they agree with the statement (Strongly agree, agree, somewhat agree, somewhat disagree, disagree, strongly disagree). The six statements were as follows: (1) "Disobeying the police is seldom justified," (2) "You should accept the decisions made by the police, even if you think they are wrong," (3) "The police can be trusted to make

decisions that are right for your community," (4) "You should do what the police tell you to do," (5) "I have confidence in the police officers who patrol my locality," and (6) "People's basic rights are well protected by the police."

The six question scale was asked at the pre-test and post-test regarding legitimacy perceptions and it was necessary to determine if all questions were considered to be part of the same factor. In order to do so, principal component analyses (PCA) and reliability analyses were conducted on the six pre-test items with no rotation. An initial analysis was run to obtain eigenvalues for each component in the data. One component had a total eigenvalue of 3.76, which is over Kaiser's criterion of 1 and explained $62.6 \%$ of the 
variance. The component matrix showed that all six items loaded on to one component with values ranging from $.65-.86$. These results indicated that the six items could indeed be combined into one factor, thus a new variable was created for an additive legitimacy score. Furthermore, analysis showed that this legitimacy scale had a high reliability, with a Cronbach's $\alpha=.82$. Generally, Cronbach's alpha is interpreted as any score over .7 indicative of high reliability (Fields, 2009). The new variable of pre-test legitimacy was created as an additive scale with lower scores indicating higher perceptions of legitimacy. The same steps were repeated on the 6 post-test items relating to legitimacy. One component had a total eigenvalue of 4.14, which is over Kaiser's criterion of 1 and explained $69.0 \%$ of the variance. The component matrix showed that all 6 items loaded on to one component with values ranging from .74 - .90. Further analysis also showed that this legitimacy scale had a high reliability, with a Cronbach's $\alpha=.91$. Like the pretest variable, the post-test legitimacy variable was created as an additive scale with lower scores indicating higher perceptions of legitimacy. A bivariate correlation analysis showed that these variables were highly correlated with one another, $r=.8, p<.01$.

\section{Independent variables}

\section{Procedural Justice, Distributive Justice, Police Performance}

These variables were measured to determine which has the largest influence of perceptions of police legitimacy. To gauge judgments of procedural justice, distributive justice, and police performance, participants were asked to respond to statements about the police on a Likert scale. 
There were seven questions on the procedural justice scale and the respondents reported how often they believed the police engaged in the specified behavior on a fivepoint scale (very often, somewhat often, sometimes, rarely, or never). The seven procedural justice statements were as follows: (1) "Treat citizens with respect and dignity," (2) "Take account of the needs and concerns of the people they deal with," (3) "Make their decisions based upon facts, not their personal biases or opinions," (4) "Give honest explanations for their actions to the people they deal with," (5) "Do not listen to all of the citizens involved before deciding what to do," (6) "Make decisions about how to handle problems in fair ways," and (7) "Treat all people fairly."

The procedural justice scale included seven items with one component having a total eigenvalue over Kaiser's criterion of 1 (4.14) and explained $69.0 \%$ of the variance. The component matrix showed that all seven items loaded on to one component with values ranging from $.59-.89$. Further analysis also showed that this procedural justice scale had a high reliability, with a Cronbach's $\alpha=.93$. The new variable of pre-test procedural justice was created as an additive scale with lower scores indicating higher procedural justice.

The distributive justice scale included three statement and participants were asked to rate on a six point Likert scale how much they agree with the statement (Strongly agree, agree, somewhat agree, somewhat disagree, disagree, strongly disagree). The three distributive justice statements were as follows: (1) "The police provide the same quality of service to all citizens," (2) "The Police enforce the law consistently when dealing with all people," and (3) "The police provide better services to wealthier citizens." 
The distributive fairness scale included three items with one component having a total eigenvalue over Kaiser's criterion of 1 (2.32) and explained $77.4 \%$ of the variance. The component matrix showed that all three items loaded on to one component with values ranging from $.76-.94$. Further analysis also showed that this distributive fairness scale had a high reliability, with a Cronbach's $\alpha=.85$. The new variable of pre-test distributive fairness was created as an additive scale with lower scores indicating higher ratings of distributive justice.

The police performance scale included three statement and participants were asked to rate on a six point Likert scale how much they agree with the statement (Strongly agree, agree, somewhat agree, somewhat disagree, disagree, strongly disagree). The three police performance statements were as follows: (1) "The police are effective in fighting crime in my neighborhood," (2) "When people call for help, the police respond quickly," and (3) "The police are effective at helping people who ask for help."

The police performance scale included three items with one component having a total eigenvalue over Kaiser's criterion of 1 (2.46) and explained $82 \%$ of the variance. The component matrix showed that all three items loaded on to one component with values ranging from $.88-.93$. Further analysis also showed that this police performance scale had a high reliability, with a Cronbach's $\alpha=.89$. The new variable of pre-test police performance was created as an additive scale with lower scores indicating higher ratings of police performance.

\section{Compliance and Cooperation}


Both cooperation and compliance have been linked to legitimacy perceptions, in that increased legitimacy is related to increased cooperation and compliance.

To measure compliance, participants were asked to respond to five statements on a five point Likert scale of how often they engage in a certain behavior (very often, somewhat often, sometimes, rarely, never). The five compliance statements were as follows: (1) "Bought something you thought might be stolen," (2) "Illegally disposed of trash and litter," (3) "Made a lot of noise at night," (4) "Drank alcohol in a place where you are not suppose to," and (5) "Broke traffic laws."

The compliance scale included five items with one component having a total eigenvalue over Kaiser's criterion of 1 (2.71) and explained $54.1 \%$ of the variance. The component matrix showed that all five items loaded on to one component with values ranging from $.68-.8$. Further analysis also showed that this compliance scale had a high reliability, with a Cronbach's $\alpha=.79$. The new variable of pre-test compliance was created as an additive scale with lower scores indicating more willingness to comply.

To measure cooperation, participants were asked to respond to three statements on a six point Likert scale of how likely they were to engage in a behavior (very likely, likely, somewhat likely, somewhat unlikely, unlikely, very unlikely). The three cooperation statements are as follows: (1) "Call the police to report a crime," (2) "Provide information to the police to help find a suspected criminal," and (3) "Call the police to report an accident".

The cooperation scale included three items with one component having a total eigenvalue over Kaiser's criterion of 1 (2.37) and explained $78.9 \%$ of the variance. The 
component matrix showed that all three items loaded on to one component with values ranging from $.86-.91$. Further analysis also showed that this cooperation scale had a high reliability, with a Cronbach's $\alpha=.87$. The new variable of pre-test cooperation was created as an additive scale with lower scores indicating more willingness to cooperate.

\section{Demographic Variables}

Participants were asked for their age, gender, race, education, and political identification. Prior police experience was coded as follows: $0=$ no prior experience, $1=$ neutral, 2 = positive, and 3 = negative. The prior victimization variable was coded as $0=$ no victimization in the last year and $1=$ at least one victimization of any kind in the last year.

Age was estimated in years from the respondent's birth year and kept as a continuous measure. The age of participants ranged from 18 to 78 , with the average age being 40.47 .

The gender variable was dichotomized $(1=$ female, $0=$ male $)$ and the sample was slightly more male than female, with $54.3 \%$ of participants identifying as male.

The survey included six racial categories to choose from: White, Black or African American, American Indian or Alaskan Native, Asian, Native Hawaiian or Pacific Islander, or Other (write in option). Due to a lower number of participants identifying as a racial minority, the race variable was dichotomized as $1=$ White and $0=$ Non-White. The racial makeup of the sample was primarily White $(80.3 \%)$. 
In regards to political affiliation, the participants were asked to choose which of the following five categories they most strongly identified with: Democrat, Republican, Independent (Left), Independent (Right), or Other (write in option). The sample was considerably more liberal, with $60.7 \%$ identifying as either democrat or independent (left) and only $32.4 \%$ identifying as either republican or independent (right).

The education measure revealed that $28.9 \%$ of participants had at least some college experience and $35.3 \%$ had a bachelor's degree. This falls in line with prior research that has found that MTurk workers tend to have a higher education level and are more liberal than the general U.S. population (Berinsky et al., 2012).

\section{Criminal Justice-Related Experiences}

Participants were asked about any experiences they have had with the criminal justice system. This will include previous victimizations as well as any other police contacts or arrests. The prior police experience variable was collected to determine if the participant ever had any interaction with the the police. This interaction could include any and all police contacts such as a traffic stop or being interviewed. The participants were further asked to rate the interaction as either positive, negative, or neutral. In this sample, 27 participants (out of 173 , or $15.6 \%$ ) reported that they never had any interaction with the police. 66 (38.2\%) reported a neutral interaction, 58 (33.5\%) reported a positive interaction, and $22(12.7 \%)$ reported a negative interaction.

Participants were also asked to report on any incidents of victimization within the past year. The questionnaire asked about incidents like, having a vehicle stolen, being robbed, or being assaulted, among other crimes. From these questions, a dichotomous 
variable was created to cover any victimization type over the previous year leading up to the survey. 97 (56\%) participants reported no victimization incidents and 76 (44\%) reported at least one victimization event. It is theorized that prior experiences with the criminal justice system may influence perceptions of legitimacy.

\section{Analytical Plan}

The first step of the analytical plan was to conduct PCA and reliability analysis on the measures. The results are reported above in the measure sections. All results indicated that they loaded on to the same factor and were reliable. Thus, it was appropriate to make new additive variables of measures of legitimacy, procedural justice, police performance, and distributive justice.

Descriptive analysis was conducted to determine if there were any concerning differences between the groups at pre-test. ANOVA and chi-square was used to examine these variables at pretest. A bivariate correlation was also conducted to examine preliminary relationship between the primary independent variables and the dependent variable of legitimacy.

The primary analysis was concerned with showing any changes in the dependent variable of legitimacy from the pretest to the post test. Analysis was conducted to show two things: 1) that there was a difference in each group between the pre-test and post-test scores and 2) that the differences of the pre- and post-tests scores between the groups are different. A post test ANOVA was conducted to determine if video exposure had an effect and a paired t-test was also conducted to examine differences from pretest mean to post test within groups. While the main focus of this primary analysis was on the 
dependent variable of legitimacy, these tests were also conducted on the independent variables of procedural justice, police performance, and distributive justice.

\section{Results}

The final sample included 173 participants and the data was analyzed using IBM's SPSS. Before analysis was conducted to determine the effect of different media exposure on the dependent variable of legitimacy perceptions, preliminary descriptive analyses were run to ensure that there were no significant differences between the groups. It was necessary to determine if the randomization into the three different groups was successful in creating three seemingly equal groups. Chi-square tests and a one-way analysis of variance (ANOVA) were used to look at possible group differences on the primary demographic variables of gender, race, education, political party affiliation, approximate age, prior police experience, prior victimization, and pre-test legitimacy. Table 1 displays the results from this preliminary analysis. The chi-square analysis sought to examine differences between the groups in categorical variables. Results of these tests produced no chi-square values that reached a point of significance (all $p \mathrm{~s}>$ $.05)$. A one-way ANOVA was conducted on the continuous variable of age and produced a non-significant F-statistic. A one-way ANOVA was also utilized to compare the group means of pre-test legitimacy scores. Results indicated that there was not a significant difference in means between the three groups $F(2,170)=.35, p=.705$. Preliminary bivariate analysis showed that there were no significant differences between the three groups and the randomization was deemed a success. Thus, changes in perceptions of 
legitimacy at post-test could not be allotted to differences in baseline measurements of legitimacy or other demographic variables.

Table 1

Demographic Differences Between the Groups

\begin{tabular}{|c|c|c|c|c|c|}
\hline \multirow[b]{2}{*}{ Variable } & \multicolumn{3}{|c|}{ Group \% } & \multirow[b]{2}{*}{$\chi^{2}$} & \multirow[b]{2}{*}{$p$} \\
\hline & Neutral & Positive & Negative & & \\
\hline Gender (Female) & 50 & 41 & 45.5 & .96 & .62 \\
\hline Race (White) & 85.7 & 75.8 & 80 & 1.84 & .40 \\
\hline Education & & & & 15.43 & .49 \\
\hline High School or Less & 8.9 & 14.5 & 10.9 & & \\
\hline Some College & 30.4 & 25.8 & 30.9 & & \\
\hline Trade School/Associates & 19.6 & 16.2 & 10.9 & & \\
\hline Bachelors Degree & 32.1 & 37.1 & 36.4 & & \\
\hline Masters or Doctorate Degree & 9 & 6.4 & 10.9 & & \\
\hline Political Affiliation & & & & 10.93 & .21 \\
\hline Democrat & 54.5 & 40.3 & 29.1 & & \\
\hline Republican & 14.5 & 27.4 & 23.6 & & \\
\hline Independent (Left) & 20 & 16.1 & 23.6 & & \\
\hline Independent (Right) & 7.3 & 11.3 & 12.7 & & \\
\hline Other & 3.6 & 4.8 & 10.9 & & \\
\hline Prior Police Experience - Type & & & & 3.91 & .69 \\
\hline None & 16.1 & 9.7 & 21.8 & & \\
\hline Neutral & 39.3 & 38.7 & 36.4 & & \\
\hline Positive & 33.9 & 35.5 & 30.9 & & \\
\hline Negative & 10.7 & 16.1 & 10.9 & & \\
\hline \multirow[t]{2}{*}{ Prior Victimization } & 44.6 & 48.4 & 38.2 & 1.25 & .54 \\
\hline & & & & $F$ & $p$ \\
\hline Age $(M)^{\mathrm{a}}$ & 39.4 & 40 & 42.1 & .56 & .57 \\
\hline Legitimacy $(M)^{\mathrm{b}}$ & 17 & 17.1 & 17.89 & .35 & .71 \\
\hline
\end{tabular}

a. Age measured as a continuous variable with a range from 18 to 78 .

b. Legitimacy measured as a continuous variable with a range from 6 to 36 .

Next, a zero-order correlation matrix was produced in order to gather preliminary information on the relationships between certain variables of interest and the dependent variable of legitimacy within the pre-test. These pre-test variables were chosen as a 
means to compare how legitimacy related to demographic variables versus the other independent variables that measured certain concepts. It was hypothesized that demographic variables would be less strongly related to legitimacy than the other independent variables that measure concepts supported by the literature on legitimacy. Table 2 presents the correlation matrix with Pearson's coefficients. In line with prior research, legitimacy perceptions were significantly positively correlated with procedural justice, $r=.70$, distributive fairness, $r=.67$, and police performance, $r=.74$ (all $p$ values $<.01)$. Thus, higher ratings of procedural justice, distributive fairness, or police performance was related to higher legitimacy perceptions. In comparison, the correlations between legitimacy perceptions and demographic variables indicated that demographics are less related to legitimacy perceptions. One demographic variable, age, was modestly related to legitimacy, $r=-.19,(p<.05)$. Due to the coding of this variables, the relationship between age and legitimacy represents that as age increases, legitimacy perceptions increase.

Table 2

Zero Order Correlations for Pre-test Variables

\begin{tabular}{|c|c|c|c|c|c|c|c|c|c|c|c|c|c|}
\hline & & 1 & 2 & 3 & 4 & 5 & 6 & 7 & 8 & 9 & 10 & 11 & 12 \\
\hline 1 & Legitimacy & - & & & & & & & & & & & \\
\hline 2 & Procedural Justice & $.697 * *$ & - & & & & & & & & & & \\
\hline 3 & Cooperation & $.448 * *$ & $.485^{* *}$ & - & & & & & & & & & \\
\hline 4 & Compliance & $.305 * *$ & $.284 * *$ & $.242 * *$ & - & & & & & & & & \\
\hline 5 & Female & -0.072 & -0.115 & -0.072 & $-.231 * *$ & - & & & & & & & \\
\hline 6 & White & -0.14 & $-.192 *$ & -0.125 & -0.024 & 0.012 & - & & & & & & \\
\hline 7 & Age & $-.194 *$ & $-.153 *$ & $-.243 * *$ & $-.219 * *$ & 0.062 & 0.081 & - & & & & & \\
\hline 8 & Education & -0.001 & 0.069 & $.176^{*}$ & 0.072 & $-.159 *$ & -0.092 & 0.086 & - & & & & \\
\hline 9 & Prior Police Experien & 0.087 & 0.149 & 0.033 & 0.148 & -0.142 & 0.077 & -0.047 & -0.043 & - & & & \\
\hline 10 & Prior Victimization & $.252 * *$ & $.191 *$ & $.241 * *$ & $.202 * *$ & 0 & -0.06 & $-.162 *$ & 0.131 & $.195^{*}$ & - & & \\
\hline 11 & Distributive Fairness & $.669 * *$ & $.757 * *$ & $.287 * *$ & $.269 * *$ & -0.125 & $-.204 * *$ & -0.09 & 0.058 & 0.089 & $.194 *$ & - & \\
\hline 12 & Police Performance & $.742 * *$ & $.648^{* *}$ & $.460^{* * *}$ & $.300^{* *}$ & -0.136 & -0.023 & -0.122 & 0.095 & 0.094 & 0.144 & $.576^{* *}$ & - \\
\hline
\end{tabular}

${ }^{*} p<.05 .{ }^{*} p<.01$ 
The main analysis of this study examined whether specific media exposure influenced legitimacy perceptions among participants. Such a change would be apparent by a difference between the pre-test and post-test legitimacy scores for each group. Furthermore, analysis was conducted to examine the prediction that different types of media would effect legitimacy perceptions differently. In other words, did the the content of the video as either, positive, negative, or neutral, produce a varying effect on changing legitimacy perceptions?

To determine if there was any effect on legitimacy perceptions due to the video exposure it was necessary to compare the results of the one-way ANOVA on the pre-test scores to the results of an ANOVA conducted on post-test legitimacy scores. If video exposure did indeed influence perceptions, we would expect to see a difference between groups on their mean post-test legitimacy scores. Recall from the previous section, that at pre-test, there were no difference between the groups on legitimacy perceptions. Results from this analysis suggested that there was a significant differences between the groups, $F(2,170)=8.53, p<.001$, thus indicating that the videos did influence legitimacy perceptions. To further investigate the overall effect a Bonferroni Post Hoc Test was conducted. The results of this test indicated that the most significant mean difference was found when comparing the negative group to both the positive and neutral group. There was a mean difference of $4.30(p<.01)$ between the negative group and neutral group and a mean difference of $4.53(p<.01)$ between the negative group and positive group, with the negative group having a mean score indicating lower legitimacy perceptions. The mean difference between the positive and neutral group was not significant. Thus, 
further suggesting that the negative videos had the greatest effect on legitimacy perceptions.

To determine if the type of media exposure did influence legitimacy perception, a paired sample t-test was carried out to determine the within-group mean differences of legitimacy. The results (found in Table 3) indicate that there was a significant difference in mean legitimacy score within each group after exposure to the specific video types. Each group saw a difference in the expected direction. The group exposed to neutral videos reported an increase in legitimacy perception after exposure with a mean difference of $1.29, t(55)=2.77, p<.01$. The positive group also reported an increase in average legitimacy perceptions with a mean difference of $1.61, t(61)=3.22, p<.01$. The negative group reported a decrease in average legitimacy perceptions with a mean difference of $-2.13, t(54)=-4.03, p<.001$. The negative group had the most significant and largest difference in mean legitimacy score, suggesting that the negative videos might have the greatest influence on perceptions. The mean difference between the positive and neutral group was slightly greater for the positive videos. This could mean that positive videos have a greater influence on increasing legitimacy perception than neutral videos, which was not originally hypothesized. This difference is too small to make any direct conclusions about the influence of positive versus neutral videos and might be a greater reflection of possible issues in the coding of the videos.

Table 3 also presents the results of paired sample t-tests carried out on other measures of interest: procedural justice, police performance, and distributive justice. The results of these tests indicate findings that are supported by previous literature. Of special 
note is that the procedural justice measure showed significant differences in pre-test and post-test in all three groups, all in the same direction as changes in legitimacy perceptions. In the neutral group, there was an increase in average procedural justice judgments, with a mean difference of $1.36, t(55)=2.55, p<.05$. There was also an increase in average procedural justice judgments in the positive group with a mean difference of $1.41, t(61)=2.73, p<.01$. The negative group saw the largest mean difference of $-3.39, t(54)=-5.26, p<.001$, highlighting the influence of procedural justice judgments when evaluating these negative videos. These procedural justice mean differences were also larger than the difference in both police performance and distributive justice. Previous literature has suggested that judgments of procedural justice are the most important antecedent when it comes to legitimacy perceptions. Thus, we can infer from these results that procedural justice was strongly linked to changes in legitimacy perceptions. We can further infer that these videos did serve as a proxy for a vicarious interaction with the police in which participants could make judgments about procedural justice. 
Table 3

Changes in Measures After Video Exposure

\begin{tabular}{lccc}
\hline \multicolumn{1}{c}{ Variable } & $M$ difference & $95 \%$ C.I. & $t$ \\
\hline Legitimacy & & & \\
Neutral & 1.29 & {$[.35,2.22]$} & $2.77 * *$ \\
Positive & 1.61 & {$[.61,2.61]$} & $3.22 * *$ \\
Negative & -2.13 & {$[-3.19,-1.07]$} & $-4.03 * * *$ \\
Procedural Justice & & & \\
Neutral & 1.36 & {$[.29,2.43]$} & $2.55^{*}$ \\
Positive & 1.41 & {$[.38,2.44]$} & $2.73 * *$ \\
Negative & -3.39 & {$[-4.68,-2.1]$} & $-5.26 * * *$ \\
Police Performance & & & \\
Neutral & .46 & {$[-.08, .99]$} & 1.72 \\
Positive & .68 & {$[.14,1.23]$} & $2.53 *$ \\
Negative & -1.44 & {$[-2.09,-.79]$} & $-4.42 * * *$ \\
Distributive Justice & & & \\
Neutral & .52 & {$[-.12,1.15]$} & 1.64 \\
Positive & .84 & {$[.28,1.4]$} & $3.02 * *$ \\
Negative & -1.7 & {$[-2.4,-1.01]$} & $-4.89 * * *$ \\
\hline$* p<.05, * * p<.01, * * *<<01$ & &
\end{tabular}

In line with prior literature, analysis was also conducted to determine if legitimacy perception changes were also related to willingness to cooperate with police activities. Results from a one-way ANOVA on the post test measure of cooperation suggested that there was a significant difference in willingness to cooperate between the three groups, $F(2,70)=21.5, p<.001$. Bonferroni's post hoc test revealed that this difference was in line with legitimacy perception changes, the mean difference between those in the negative group and neutral group was 4.72, $p>.001$ and the mean difference between the negative group and positive group was 5.56, $p>.001$. There was not a significant difference between the neutral and positive group. Comparing the groups, those in the negative group reported that they were less likely to cooperate with police 
activities after watching the videos, while those in both the positive and neutral group reported that they were more likely to cooperate.

\section{Discussion}

\section{Limitations}

Studies that seek to address media effects will always suffer limitations in that is difficult to gauge the highly nuanced, non-linear influence of media. The effects of the media are cumulative and happen over extended periods of time (Callanan and Rosenberger 2011). Since this study only looks at immediate exposure and uses a survey measure, the data may not capture all significant findings. The data cannot account for what else occurs over the long term. The findings here do indicate that in the short term, media exposure can influence legitimacy perceptions, but it has not been determined what might occur over the long term. It is possible that the influence may erode over time.

Furthermore, the coding of the videos might suffer reliability issues. Any person viewing a video will do so through their own unique perspective and there will be variation in how other's might rate the videos. In this study, specific methods were enacted to try increase the reliability of video coding. There was some overlap between how the external raters categorized positive and neutral videos. There was a greater degree of consensus when rating negative videos that showed police acting in a way considered to be procedurally unjust. As addressed previously, it is possible that when police act in a way that is procedural just, this could be perceived as positive by a judger. 
In this study, positive videos were associated more with community building and activities that fall outside the typical duties of police officers. Nonetheless, given the detailed literature on procedural justice, coding videos as procedurally just should be reliable (Sunshine \& Tyler, 2003; Tyler 1990, 2003; Tyler \& Huo, 2002). Videos that were coded as neutral (procedurally just) were clips that showed the police officer engaging in a typical duty in a way that was respectful, gave the citizen voice, and carefully explained the motives and reasoning for their actions.

To further ensure the reliability of the video rating, the participants were also asked to rate the videos after viewing. For the most part, participants rated the video as the intended category. A frequency analysis of the participant's ratings revealed that on 13 of the 15 videos the majority of the participants rated the video as was intended, with a range varying from $58.2 \%$ to $96.3 \%$ of the subjects in agreement. There were two videos that were rated in a way that showed a stronger divide. As mentioned before, it was suggested that there might be an overlap between positive and neutral videos. There was one neutral video that was rated as neutral by $48.2 \%$ of viewers and as positive by $46.4 \%$ of viewers. The content of this video displayed a police officer during a traffic stop acting respectful with the citizens in the car. The reason that this video might have been perceived as more positive than just simply neutral, is that the police officer and citizen's appeared to know one another, and the driver of the car appeared to be involved with an organization that go out of their way to watch police and record their behavior. Thus, there was a rapport between the police officer and the citizen that could have been perceived as extra friendly, and not just a typically, routine duty. Even though the 
majority of viewers did rate it as the intended category, it still cast some doubt over the appropriate label for the content of this video.

Another video that was intended to be "positive" was rated by $50 \%$ of the viewers as neutral, whereas $48.4 \%$ of the viewers rated it as positive. The content of this video showed a few police officers talking with a group of 15-20 teenagers who are loitering in a parking lot. In the video the officer explains why they can not be out loitering, how he does not want to write any tickets, and explains to them what they can do instead. In some ways, this interaction falls in line with the neutral/fair category because it could be seen as an officer engaging in a typical duty. The external raters who categorized this video saw it as slightly more positive than neutral. The police officers are engaging with the community and are going above and beyond intended duties. Furthermore, Tyler (2004) has suggested that participation is a key component of procedural justice, meaning that people see a procedure as more fair if they are given a chance to explain and communicate their views. In this video, the citizens are shown merely as listening subjects while the police officer was delivering a lecture of sorts. Thus, it was determined that this video fell more in line with the positive category. While these two cases might cast doubt on the reliability of the video coding, the fact that a rather sizable portion of viewers did indeed rate them as the intended category and that the other videos did not suffer any issues, should diminish any concern. Future research is advised to develop a more detailed approach to video coding. Perhaps a system of coding could be used to count the number of procedurally just elements a video contains and the videos could be rated on a sliding scale of procedural fairness. 
Compared to other online surveys the sample size of this study might be considered too small, but it was an appropriate number to detect an effect. The sample might also have some demographic differences with the population at large which could result in generalizability issues. This should not be of as great a concern considering the large amount of literature on the reliability of using MTurk for social experiments. Furthermore, MTurk workers tend to be closer to the U.S. Population as a whole than traditional university subject pools (Paolacci et al., 2010).

The lack of diversity within the sample is a concern that should be considered. The sample was $80 \%$ white and we know from prior research that there are racial differences in regards to views towards the police and interactions with the police. National polls have shown that African Americans generally hold a more negative views towards the police and have less confidence in the police's ability to protect them. In comparison to white citizens, African Americans display greater adverse reactions to incidents of police brutality and these incidents have greater longevity towards changings their perceptions (Tuch \& Weitzer, 1997). Furthermore, only $12.7 \%$ of the participants in this study reported having a negative interaction with the police previously, which might have been different if the sample was more diverse. Those who live in poor neighborhoods, which tend to have a high concentration of racial minorities, often experience different forms of policing strategies, leading to different types of interactions and views towards the police (Tyler \& Fagan, 2008). It is suggested that future research, that wishes to further test the results found in this study, attempts to over sample racial minorities. 
Lastly, there are inherent limitations to survey data including the fact that it does not provide in-depth explanations or reasons behind certain attitudes. Each participant who watched the videos, examined the information through their own unique perspectives. There could be certain reasons why a video might influence one person's mind over another's. Due to the limited nature of the survey data it is hard to determine what exactly influenced a participants change in perceptions, but going off of prior literature, that suggests that procedural justice is equally important across all individuals, we can gather that changes were due to judgments made about the officer's actions and procedures. Furthermore, it was appropriate to use survey as the methodology considering the large body of literature on legitimacy that has also used this methodology. This allowed the opportunity to use scales and measure that have previously been found valid, thus increasing the validity of the current study. Therefore, the results found here can add important information to the existing body of literature.

\section{Conclusion}

This study sought to examine the influence that video clips of police-citizen interactions could have on legitimacy perceptions. Prior research has shown that people form their legitimacy perceptions by judging the actions of the police during encounters (Tyler \& Huo, 2002). It was hypothesized that this might also be the case when people watched raw video footage of such encounters. This is especially important to examine given the changes in police-citizens relations over the past few years. It is becoming more and more common to share videos of police on the internet and many people have been 
exposed to such videos. In this sample, only seven people out of 173 (4\%) claimed to have never seen a police-citizen video clip on social media before and $26.6 \%$ of the sample responded that they see such clips at least weekly. The ability for people to engage in this type of citizen-journalism could have drastic effects on views towards the police. In the past, police often had the upper hand when it came to controlling their image in the media, but this is beginning to change. Whereas police often were considered and can still be considered the ultimate "watchers" who enact surveillance on every day citizens, this power relation is not as straight forward anymore. Currently, there appears to be attempts from the public to reverse the roles by engaging sousveillance, where the many (the public) are watching the actions of the few (the police).

This new and changing dynamic led to an important question, is this attempt of watching the police and sharing video content with the public actually influencing people's perceptions? The results of this study indicate that there is an influence, at least initially, from such actions. After exposure to video clips, participant's perceptions were changed and the greatest change could be seen in the group exposed to negative videos. Those who watched clips of police acting in a way that was not in line with procedural justice or was an example of possible excessive use of force, perceived the police as less legitimate. Those who watched positive or neutral videos, subsequently viewed the police as more legitimate, but this change in perception was not as large as the change found in the negative group.

The results of this study holds implications for both the public and the police. For citizens wishing to increase police transparency and accountability it is appears that 
methods of sousveillance can be an effective approach. By sharing information that could decrease legitimacy perception this could lead to more pressure being placed on the police for appropriate reform. Policing organizations will further benefit from the results of this study in so far as they can work towards increasing legitimacy perceptions. The results show that certain types of videos help to increase legitimacy perceptions, thus, it would be in the best interest of the police to use such methods. This is especially important given the link between legitimacy and cooperation cited throughout the literature and also supported in this study. Those who watched positive or neutral videos not only reported an increase in legitimacy perceptions, they also reported that they would be more likely to cooperate with police activities like reporting criminal activities and providing information about a potential suspect to the police. This cooperation is essential as the police rely a great deal on help and information from the public in order to perform their duties effectively and maintain public safety. Police departments would be well advised to engage in social media outreach with video footage that show them acting in ways that are positive and procedurally just. 


\section{Reference List}

Antony, M. G., \& Thomas, R. J. (2010). 'This is citizen journalism at its finest':

YouTube and the public sphere in the Oscar Grant shooting incident. New Media \& Society, 12, 1280-1296.

Bernard, E. (2015). Between the world and me: Black American motherhood. The Atlantic Monthly.

Berinsky, A. J., Huber, G. A., \& Lenz, G. S. (2012). Evaluating online labor markets for experimental research: Amazon. com's Mechanical Turk. Political Analysis, 20(3), 351-368.

Braga, A. A., Winship, C., Tyler, T. R., Fagan, J., \& Meares, T. L. (2014). The salience of social contextual factors in appraisals of police interactions with citizens: a randomized factorial experiment. Journal of Quantitative Criminology, 30(4), 599-627.

Callanan, V. J., \& Rosenberger, J. S. (2011). Media and public perceptions of the police: examining the impact of race and personal experience. Policing \& Society, 21(2), 167-189.

Chermak, S., \& Weiss, A. (2005). Maintaining legitimacy using external communication strategies: An analysis of police-media relations. Journal of Criminal Justice, 33(5), 501-512.

Chiricos, T., Eschholz, S., \& Gertz, M. (1997). Crime, news and fear of crime: Toward an identification of audience effects. Social problems, 44(3), 342-357.

Derickson, K. D. (2016). The racial state and resistance in Ferguson and beyond. Urban Studies, 53(11), 2223-2237.

Eschholz, S., Blackwell, B. S., Gertz, M., \& Chiricos, T. (2002). Race and attitudes toward the police: Assessing the effects of watching "reality" police programs. Journal of Criminal Justice, 30(4), 327-341.

Farmer, A. K., \& Sun, I. Y. (2016). Citizen Journalism and Police Legitimacy: Does Recording the Police Make a Difference?. In The Politics of Policing: Between Force and Legitimacy, 239-256. Emerald Group Publishing Limited. 
Funder, D. C., Levine, J. M., Mackie, D. M., Morf, C. C., Sansone, C., Vazire, S., \& West, S. G. (2014). Improving the dependability of research in personality and social psychology: Recommendations for research and educational practice. Personality and Social Psychology Review, 18(1), 3-12.

Gerbner, G., Gross, L., Signorielli, N., \& Morgan, M. (1980). Aging with television: Images on television drama and conceptions of social reality. Journal of Communication, 30(1), 37-47.

Graziano, L., Schuck, A., \& Martin, C. (2010). Police misconduct, media coverage, and public perceptions of racial profiling: An experiment. Justice Quarterly, 27(1), $52-76$.

Greer, C., \& McLaughlin, E. (2010). We predict a riot? Public order policing, new media environments and the rise of the citizen journalist. British Journal of Criminology, 50(6), 1041-1059.

Jackson, J., Bradford, B., Hough, M., Myhill, A., Quinton, P., \& Tyler, T. R. (2012). Why do people comply with the law? Legitimacy and the influence of legal institutions. British Journal of Criminology, 52(6), 1051-1071.

Jonathan-Zamir, T., \& Weisburd, D. (2013). The effects of security threats on antecedents of police legitimacy findings from a quasi-experiment in Israel. Journal of Research in Crime and Delinquency, 50(1), 3-32.

Lawler, E. J., Ford, R. S., \& Blegen, M. A. (1988). Coercive capability in conflict: A test of bilateral deterrence versus conflict spiral theory. Social Psychology Quarterly, 51(2), 93-107.

Lersch, K. M., \& Hart, T.C. (2011). Space, time, and crime ( $3^{\text {rd }}$ ed.). Durham, NC: Carolina Academic Press.

Livingstone, S., Allen, J., \& Reiner, R. (2001). Audiences for crime media 1946-91: A historical approach to reception studies. The Communication Review, 4(2), 165192. 
Meijer, A., \& Thaens, M. (2013). Social media strategies: Understanding the differences between North American police departments. Government Information Quarterly, 30(4), 343-350.

Murphy, K., Hinds, L., \& Fleming, J. (2008). Encouraging public cooperation and support for police. Policing \& Society, 18(2), 136-155.

Paolacci, G., Chandler, J., \& Ipeirotis, P. G. (2010). Running experiments on amazon mechanical turk. Judgment and Decision Making, 5(5), 411-419.

Pew Research Center. (2016). The Modern News Consumer.

President's Task Force on 21st Century Policing. (2015). Final Report of the President's Task Force on 21st Century Policing. Washington, DC: Office of Community Oriented Policing Services.

Reisig, M. D., Bratton, J., \& Gertz, M. G. (2007). The construct validity and refinement of process-based policing measures. Criminal Justice and Behavior, 34, 10051028.

Romer, D., Jamieson, K. H., \& Aday, S. (2003). Television news and the cultivation of fear of crime. Journal of communication, 53(1), 88-104.

Rosenbaum, D. P., Graziano, L. M., Stephens, C. D., \& Schuck, A. M. (2011). Understanding community policing and legitimacy-seeking behavior in virtual reality: A national study of municipal police websites. Police Quarterly, 14(1), $25-47$.

Ross, J., Irani, L., Silberman, M., Zaldivar, A., \& Tomlinson, B. (2010, April). Who are the crowdworkers?: shifting demographics in mechanical turk. In CHI'10 extended abstracts on Human factors in computing systems (pp. 2863-2872). ACM.

Sargeant, E., Murphy, K., \& Cherney, A. (2014). Ethnicity, trust and cooperation with police: Testing the dominance of the process-based model. European Journal of Criminology, 11(4), 500-524.

Shapiro, D. N., Chandler, J., \& Mueller, P. A. (2013). Using Mechanical Turk to study clinical populations. Clinical Psychological Science, 1-8. 
Steblay, N. M., Besirevic, J., Fulero, S. M., \& Jimenez-Lorente, B. (1999). The effects of pretrial publicity on juror verdicts: A meta-analytic review. Law and Human Behavior, 23(2), 219-235.

Stewart, N., Ungemach, C., Harris, A. J., Bartels, D. M., Newell, B. R., Paolacci, G., \& Chandler, J. (2015). The average laboratory samples a population of 7,300 Amazon Mechanical Turk workers. Judgment and Decision Making, 10(5), 479.

Studebaker, C. A., \& Penrod, S. D. (1997). Pretrial publicity: The media, the law, and common sense. Psychology, Public Policy, and Law, 3(2-3), 428.

Sunshine, J., \& Tyler, T. R. (2003). The role of procedural justice and legitimacy in shaping public support for policing. Law \& Society Review, 37(3), 513-548.

Tuch, S. A., \& Weitzer, R. (1997). Trends: Racial differences in attitudes toward the police. The Public Opinion Quarterly, 61(4), 642-663.

Tyler, T. R. (1990). Why people obey the law: Procedural justice, legitimacy, and compliance. Yale University Press, New Haven.

Tyler, T.R. (1994). Governing amid diversity: Can fair decision-making procedures bridge competing public interests and values? Law and Society Review 28, 70122.

Tyler, T.R. (2000). Multiculturalism and the willingness of citizens to defer to law and to legal authorities. Law and Social Inquiry 25(3), 983-1019.

Tyler, T. R. (2001). Trust and law abidingness: A proactive model of social regulation. Boston University Law Review, 81, 361-406.

Tyler, T. R. (2003). Procedural justice, legitimacy, and the effective rule of law. Crime and Justice, 30, 283-357.

Tyler, T. R. (2004). Enhancing police legitimacy. The Annals of the American Academy of Political and Social Science, 593(1), 84-99.

Tyler, T. R. (2005). Policing in black and white: Ethnic group differences in trust and confidence in the police. Police quarterly, 8(3), 322-342.

Tyler, T. R., \& Fagan, J. (2008). Legitimacy and cooperation: Why do people help the police fight crime in their communities? Ohio State Journal of Criminal Law, 6, 231. 
Tyler, T. R., \& Huo, Y. (2002). Trust in the Law: Encouraging Public Cooperation with the Police and Courts. Russell Sage Foundation, New York.

Weitzer, R. (2015). American policing under fire: Misconduct and reform. Society, 52(5), 475-480.

Weitzer, R. (2002). Incidents of police misconduct and public opinion. Journal of Criminal Justice, 30(5), 397-408.

Wolfe, S. E. (2011). The effect of low self-control on perceived police legitimacy. Journal of Criminal Justice, 39(1), 67-74. 